Contributors: The original idea for the study arose jointly in a meeting of the three authors. GV and $\mathrm{MH}$ designed and piloted the questionnaire, and all three authors collected data and jointly wrote the paper. $\mathrm{MH}$ performed the statistical analysis. $\mathrm{MH}$ acts as the guarantor of the paper.

Funding: None.

Competing interests: None declared. al. Results of the Harvard medical practice study I. Incidence of adverse events and negligence in hospitalized patients. $N$ Engl $J$ Med 1991;324:370-6.

2 Laurance J. Doctors warned on care of patients. Independent $1998 \mathrm{May}$ 20:5.

General Medical Council. Good medical practice. London: GMC, 1998.

4 Leape L. Error in medicine. JAMA 1994:272:1851-7.

5 Vincent C, Young M, Phillips A. Why do people sue doctors? A study of patients and relatives taking legal action. Lancet 1994;343:1609-13.

(Accepted 10 December 1998)

\title{
Cross sectional survey of cervical cancer screening in women with learning disability
}

\author{
Ken Stein, Nick Allen
}

Evidence exists that cervical smears are rarely offered to women with learning disability. ${ }^{1}$ We examined whether women with learning disability were being offered and were accepting screening.

\section{Methods and results}

All residents with learning disability in one English health district who were known to health or social services were identified from the computer records of the local community health services trust and the social services department. Records were adjusted for double counting, and women eligible for cervical screening were defined as all women aged 20-64 years.

Screening histories were checked against the records of the cervical cancer screening programme. To preserve confidentiality the data collection manager who checked the records was blind to the nature of the population under study. The proportion of eligible women screened was compared with available data for the whole district.

The local ethics committee advised that the study, which was part of an audit programme, did not require ethical approval provided that nothing was to be done to the people concerned and adequate steps were taken to ensure that confidentiality was maintained.

In all, 389 of the 461 women (age range 18-94 years) identified in the overall sample of 969 residents (giving a district prevalence of learning disability of 2.2 per 1000) were eligible for cervical screening.

Forty nine (13\% (95\% confidence interval $9 \%$ to $16 \%)$ ) of the eligible women had a record of a smear test in the previous five years. Two (4\%) had inadequate smear tests, and one had follow up of a previously abnormal test. No significant differences in mean age were seen between women screened and those not screened (40.4 years $v 37.4$ years). Coverage in women with learning disability was markedly lower than for the general district population (which was $88 \%$ in 1992-32).

\section{Comment}

The sample population of residents with learning disability probably did not include the entire district population with learning disabilities; prevalence was lower than expected (2.5 to 4 per 1000 population) and may have included people without learning disability who are in contact with those services-for example, people with brain injury acquired in adolescence).
However, such misclassification is unlikely to account for the results.

Coverage in the cervical cancer screening programme is markedly lower for women with learning disability than for the general female population. We were not able to make appropriate exclusions on the grounds of hysterectomy, although the number to whom this would apply is probably small. It is difficult to say whether the poorer coverage in women with learning disability is inequitable or reasonable as little is known about the incidence of cervical cancer in this population group. In the general female population cervical cancer is clearly related to sexual activity. Assumptions, however, that people with learning disability are sexually inactive may be wrong. ${ }^{34}$ Moreover, although the incidence of cervical cancer is extremely low in women who have never been sexually active, we believe that such women should still be invited for screening-if only to record the grounds on which they have been excluded from the screening programme.

Additional factors that may contribute to limited access and may be amenable to change include low demand for screening from women with learning disability; perceived difficulty in obtaining consent for screening ${ }^{5}$; difficulties with using appointment systems and waiting rooms; uncertainty about whether general practitioners or specialist teams are responsible for routine care; poor liaison with specialist services; inadequate training of general practitioners in communication skills; pressure of competing demands from other groups of patients.

Further research is needed into the effectiveness and efficiency of screening and, perhaps most importantly, into acceptability of screening by women with learning disabilities.

Contributors: KS and NA designed the study after an original idea by NA. KS carried out data collection and analysis. Both authors drafted the final manuscript. KS is the guarantor for the paper.

Funding: No special funding.

Competing interests: None declared.

1 Royal College of General Practitioners. Primary care for people with mental handicap. London: RCGP, 1990. (Occasional paper 47.)

2 Allen N. Annual report of the director of public health. Southampton: Southampton and South West Hants Health Commission, 1994.

3 Reid DA. Sexual activity in people with profound learning disabilities. $\mathrm{Br}$ J Learning Disability 1995;23:56-8.

4 Beail N, Warden S. Sexual abuse of adults with learning disabilities. Journal of Intellectual Disability Research 1995;39:382-7.

5 Haire A, Bambrick M, Jones J. Cervical screening for women with a mental handicap. Br J Fam Planning 1992;17:120-1.

(Accepted 10 December 1998)
Southampton and South West Hants Health Authority, Southampton SO16 4GX

Ken Stein, senior registrar Nick Allen, director of health strategy and public health

Correspondence to: Dr K Stein, Wessex Institute for Health Research and Development, Boldrewood, University of Southampton, Highfield, Southampton SO15 2GS

BMJ 1999;318:641 